\title{
Evaluation of two self-report measures of physical activity with accelerometry in young adults
}

\author{
John R Sirard ${ }^{1}$, Peter J Hannan², Gretchen J Cutler², Dan J Graham², and Dianne Neumark- \\ Sztainer ${ }^{2}$ \\ Peter J Hannan: hanna001@umn.edu; Gretchen J Cutler: cutle007@umn.edu; Dan J Graham: djgraham@umn.edu; \\ Dianne Neumark-Sztainer: neuma011@umn.edu \\ ${ }^{1}$ Kinesiology Program, Department of Human Services, University of Virginia, Curry School of \\ Education \\ ${ }^{2}$ Division of Epidemiology and Community Health, University of Minnesota School of Public \\ Health
}

\begin{abstract}
Background-The purpose of this paper is to evaluate self-reported physical activity of young adults using one-week and one-year recall measures with an accelerometer as the criterion measure.

Methods-Participants were a subsample ( $\mathrm{N}=121,24 \pm 1.7 \mathrm{yrs})$ from a large longitudinal cohort study. Participants completed a detailed one-year physical activity recall, wore an accelerometer for one week and then completed a brief one-week physical activity recall when they returned the accelerometer.
\end{abstract}

\begin{abstract}
Results-Mean values for moderate-to-vigorous physical activity (MVPA) from the three instruments were 3.2, 2.2, and 13.7 hours/wk for the accelerometer, one-week recall, and one-year recall, respectively (all different from each other, $\mathrm{p}<0.001$ ). Spearman correlations for moderate, vigorous, and MVPA between the accelerometer and the one-week recall $(0.30,0.50$, and 0.40 , respectively) and the one-year recall $(0.31,0.42$, and 0.44 , respectively) demonstrated adequate validity.
\end{abstract}

Conclusions-Both recall instruments may be used for ranking physical activity at the group level. At the individual level, the one-week recall performed much better in terms of absolute value of physical activity. The one-year recall overestimated total physical activity but additional research is needed to fully test its validity.

\section{Keywords}

physical activity assessment; measurement; motion sensors; instrument psychometrics

\section{INTRODUCTION}

Low levels of physical activity and high amounts of sedentary time are major public health concerns across the life span. ${ }^{1}$ Previous studies have indicated that physical activity begins to decline in early adolescence and this decline continues into young adulthood. ${ }^{2-5}$

Longitudinal data from the Longitudinal Study of Adolescent Health indicates that meeting

Corresponding Author: John R Sirard, PhD, Kinesiology Program and Youth-Nex, Curry School of Education, University of Virginia, 210 Emmet Street South, Suite 203, Charlottesville, VA 22904, Sirard Phone: (434) 243-5189, Sirard Fax: (434) 924-1389,

jrs2wq@virginia.edu. 
physical activity recommendations declines from about one-third of adolescents to less than $13 \%$ in young adulthood. ${ }^{6}$ Nelson et al. also reported significant declines in moderate-tovigorous physical activity (MVPA) from 16 to 20 years old (especially in females), using longitudinal cohort data from the Eating and Activity among Teens study (Project EAT). ${ }^{7}$ To better understand and promote physical activity, especially during critical transitional life stages, accurate methods for assessing physical activity behavior are needed.

Accelerometers have become increasingly popular for physical activity assessment. However, their relatively higher cost compared to surveys ${ }^{8}$ and the personnel requirements for initializing, downloading, and tracking of monitors limits their use in larger studies. In addition, uncertainty about accelerometer data reduction procedures and an inability to identify specific activities engaged in or the environmental contexts related to those activities also prevents more universal usage. ${ }^{9}$ For large epidemiological studies, the cost and logistics of collecting accelerometer data from all participants may be beyond the resources available. Thus, there is a continued need for valid physical activity questionnaires. While there are a number of self-report instruments that are suitable for adult populations, each research study brings with it certain demographic and research design constraints that require modifications to existing surveys or outright development of new instruments. With either course of action, the survey method should be validated with a stronger criterion measure, typically an accelerometer. ${ }^{10}$

The Godin-Shephard (G-S) recall, ${ }^{11}$ a one-week recall instrument that assesses leisure-time activity, has been previously validated for adolescents and adults. ${ }^{11-13}$ The G-S recall is attractive for use in large studies because of its short length (three questions). While the G-S recall has been previously validated, it has not been evaluated using a contemporary accelerometer combined with sophisticated data processing techniques.

Other more detailed questionnaires offer the potential to capture additional information about a participant's physical activity patterns and the types of activities performed. The Growing Up Today Study (GUTS) ${ }^{14}$ has used a more detailed one-year recall, divided into seasons, ${ }^{15}$ to assess physical activity levels and specific activities over a longer time period than the more typical three-day or one-week recall. This longer recall time frame may be particularly appropriate for longitudinal studies with relatively long periods of time between assessments. No previous study has compared this one-year recall with the criterion of accelerometer data.

The purpose of this study was to evaluate the physical activity estimates obtained from the one-week G-S Recall and a modified GUTS One-Year Recall compared to the criterion measure of one-week of accelerometer data in young adults participating in the third wave of the Eating and Activity among Teens study (Project EAT-III). A second purpose was to determine if gender, minority status, or weight status moderated these associations.

\section{METHODS}

\section{Study Design}

The data used for this paper were obtained from a sub-sample of participants in Project EAT-III, a population-based study investigating the socio-environmental, personal and behavioral determinants of dietary intake, physical activity, and weight-related variables among a large and ethnically diverse adolescent population. ${ }^{16}$ Details about previous waves of Project EAT can be found elsewhere. ${ }^{17,} 18$ The original Project EAT-I participants (19981999) were measured when they were in their $7^{\text {th }}$ and $10^{\text {th }}$ grade years. Approximately ten years later (2009-2010) Project EAT-III contacted all of the original participants ( $\mathrm{N}=$ 2284). 
After completing the Project EAT-III survey, which included the One-Week G-S recall and the One-Year Recall instrument, participants were recruited by email to participate in a substudy designed to enroll 120 participants. Participants in the main sample were stratified by gender, race (white or non-white), and weight status (non-overweight or overweight/obese) derived from self-reported height and weight. The non-overweight category was based on a BMI $\left(\mathrm{kg} / \mathrm{m}^{2}\right)$, calculated from self-reported height and weight, of less than 25 . The participant's self-reported BMI from the survey was used for contacting potential participants. However, measured BMI taken at the initial office visit was used to satisfy the overweight/non-overweight category for the quota sampling. The correlation between selfreported and measured BMI indicated a strong association $(r=0.97)$ although the self-report and measured means were statistically significantly different ( $27.7 \pm 7.0$ vs. $28.4 \pm 7.2$, respectively, dependent t-test $\mathrm{p}<0.01$ ). The measured BMI is used for all of the analyses.

Those participants who were selected to participate in the sub-study but were then determined to live outside of the Minneapolis/St. Paul Metro area or declined to participate were replaced by other participants randomly selected from the same gender, race, and weight status strata. At an office visit, participants provided consent for the sub-study procedures, were measured for height and weight, and then given an accelerometer to wear for one week. After one week, accelerometers and a second completed One-Week G-S recall were mailed back to study staff using a pre-paid envelope. Test-retest reliability coefficients between the first and second G-S recalls were 0.39 for light, 0.43 for moderate, 0.60 for vigorous, and 0.57 for MVPA. Based on these correlations and the timing of the second survey (immediately followed the accelerometer protocol) data from only the second G-S recall are used in the analyses.

\section{Sample}

We attempted to contact approximately 250-300 participants, with the majority not accepting the invitation to participate in the current accelerometer study. A small number of individuals agreed to participate but could not be scheduled for an appointment. A total of $\mathrm{N}=126$ participants completed the accelerometer protocol but, based on the exclusion criteria for the accelerometer data, $\mathrm{n}=5$ individuals were eliminated from the analyses. Therefore, the analytical sample is $\mathrm{n}=121$ participants $(24 \pm 1.7$ years old $)$ evenly distributed across the gender (50\% male), race (50.8\% white), and weight status strata (53.4\% overweight or obese), as designed. Chi-square analyses of gender $\mathrm{x}$ race, gender $\mathrm{x}$ weight status and race $\mathrm{x}$ weight status associations were not significant $(\mathrm{p} \geq 0.46)$ indicating that subjects were evenly distributed within each sub group.

\section{Measures}

Godin-Shephard One-Week Physical Activity Recall-The Godin-Shephard (G-S) recall is a one-week recall instrument that asks the participant to recall the amount of time in the previous week he/she spent in "strenuous," "moderate," and "mild" intensity exercise. Examples for each intensity level are provided, including general physical activities (e.g., walking, dancing) in addition to structured exercise and sport examples (e.g., aerobic dance, running, soccer). The One-Week G-S recall has been previously validated in adolescent and adult populations using several different criterion measures; Caltrac accelerometer $(\mathrm{r}=0.32$ to 0.45$)^{11,19}$, aerobic fitness ( $\mathrm{r}=0.38$ to 0.56$)^{11,20}$, and other physical activity questionnaires $(\mathrm{r}=0.36 \text { to } 0.61)^{12,13,19,20}$ and a modified version has been used in previous waves of Project EAT. 7, 21, 22 The six response options ranged from "None" to "6+ hours a week." The mid-point of each response option was used to calculate time (hours per week) spent in each intensity category and total moderate-to-vigorous physical activity (MVPA) (sum of strenuous and moderate). One-week test-retest reliability of the G-S Recall in a separate sample of 66 young adults was $r=0.85$. 
EAT-III One-Year Physical Activity Recall-The One-Year Recall used for this study was modified from the seasonal version of the Growing Up Today Study's (GUTS) one-year recall. ${ }^{15,23}$ The original instrument has moderate one-year test-retest reliability for vigorous physical activity in a sample of 262 high school students $(r=0.55$ for girls, $r=0.61$ for boys). Hours per week of vigorous physical activity was inversely associated with 1-mile run time ( $r=-0.41$ for girls, $r=-0.48$ for boys) in a larger sample of 1035 high school students. ${ }^{24}$ In a separate sample of 114 high school students, the Spearman correlation between vigorous physical activity from the GUTS and from three 24-hour recalls was 0.63 . ${ }^{24}$ A modified form of the seasonal version of the GUTS tool ${ }^{15}$ was used due to the large differences in weather conditions that occur in the upper Midwest, where the participants for the current study lived. The GUTS seasonal tool resulted in lower estimates of total activity compared to the original version, particularly for activities not performed on a regular basis throughout the year. ${ }^{15}$

For Project EAT-III, the GUTS seasonal tool was modified due to the older age of the current sample. Modifications included separate sections for work and transportation physical activity, the addition/substitution of specific activities (e.g., added yoga/pilates, removed cheerleading), and slight modifications to the response categories. The One-Year Recall was divided into work-related activity ( 3 items; vigorous, moderate, and light/ sedentary work activity), transportation physical activity ( 2 items; walking and biking to get to places), and free time activities (24 items plus two "other" write-in options). For each question, the participant was asked if he/she did the activity. If the respondent indicated "yes," he/she was directed to report how much time was spent per week in that activity for each season separately. The seven response options ranged from "None/Zero" to " $10+\mathrm{hr} /$ wk." An example of the question formatting is provided in Figure 1 and the full instrument is available from the first author. Time spent in each activity for each season was calculated using the midpoint of the chosen response option, similar to the data processing for the OneWeek G-S Recall. For the whole year, hours per week values were summed across all seasons. Individual activities were categorized by intensity (moderate $=3$ to 5.9 METS, or vigorous $\geq 6$ METS) using the compendium of physical activities. ${ }^{25}$

Accelerometer-The ActiGraph physical activity accelerometer, model GT1M (ActiGraph, LLC, Pensacola, FL) was used to collect seven consecutive days of physical activity data. The monitor is an objective measure of physical activity and has been previously validated for use with children and adolescents in laboratory and field settings. ${ }^{26-28}$

The monitors were set to begin collecting data in 30-second intervals (epochs) at the time of the participant's clinic visit. Trained research staff fit an elastic belt with an attached monitor to each participant's right hip, according to a standardized protocol. Participants were given written and verbal instructions on the use and care of the monitor. They were instructed to wear the monitor during all waking hours except when swimming and bathing. Participants were encouraged to call study staff with any questions or problems they encountered with the monitor and given a pre-paid envelope for the return of the monitor following the data collection period. Upon return, the data from each monitor were downloaded to a computer for subsequent data reduction and analysis.

ActiGraph data were reduced using a custom developed software program. ${ }^{29}$ All data contained within the time frame starting from when the monitor was initialized until the same time the following week were processed. For days 2 through 7, data from 12:00:30 in the morning until midnight were reduced to summary variables. Partial data from days one and eight (when the accelerometer was received and returned, respectively) were combined to form a composite seventh day. ${ }^{29,30}$ 
Daily inclusion criteria were established to determine days and times with acceptable accelerometer data. Blocks of time incorporating at least 30 continuous minutes of "0" output were considered to be times when the participant was not wearing the monitor. 30,31 These blocks of zeroes were eliminated and not used in any calculations. Days with less than 10 hours of data were considered to be incomplete and were eliminated from data reduction procedures. ${ }^{30,32,33}$ Finally, only participants with at least four out of seven days of data were retained for these analyses. ${ }^{34}$ No data were imputed for these analyses.

After applying inclusion criteria to the data, summary physical activity variables were calculated. Time spent in moderate, vigorous, and MVPA were calculated as the mean hours per week spent in each intensity category. The time spent in these intensities were calculated using the light, moderate and vigorous intensity cutpoints (100, 2,020 and 5,999 counts per minute, respectively) recently used for accelerometer data from a nationally representative sample of adults. ${ }^{35}$ Because data for the current study were collected in 30 -second epochs, the cutpoints were halved (i.e., 50, 1,010 and 3,000 counts per minute for light, moderate and vigorous physical activity, respectively).

Weight Status-In addition to self-reported height and weight from the survey, participants were measured for height to the nearest $0.1 \mathrm{~cm}$ using a stadiometer (Schorr Productions, Olney, MD) and weight to the nearest $0.1 \mathrm{~kg}$ using a calibrated digital scale (SECA) by trained project staff.

Demographics-In addition to gender and race, participants were asked to select the highest level of education they had attained and if they had received any form of public assistance during the previous year. In addition, participants reported who they lived with during the previous year and the number of children with whom they lived.

\section{Statistical Analysis}

All accelerometer variables (except average hours per week spent in light intensity physical activity) were non-normally distributed. These non-normal values were log-transformed for analyses. Independent t-tests were used to determine differences in physical activity variables between genders, racial groups (i.e. white vs. nonwhite), and measured weight status (i.e. BMI <25 vs. BMI 25 ). Spearman correlations were calculated to compare accelerometer-derived variables and self-reported physical activity variables for the full sample and by gender, minority status, and measured weight status. General linear models were used to determine if these characteristics moderated the association between accelerometer recorded and self-reported physical activity. Scatter plots and Bland-Altman plots were generated to visually compare accelerometer-derived and self-reported MVPA. SAS version 9.1 (Cary, NC) was used for all analyses.

\section{RESULTS}

Thirty-six percent of the participants had a high school degree or less, and 36\% had at least a bachelor's degree; the remaining $28 \%$ had an associate's degree or vocational/technical training. Nine percent of participants received some form of public assistance during the previous year. Twenty percent of the sample lived with their spouse during the previous year and $23 \%$ of the sample had at least one child.

On average, the 121 participants wore the accelerometer for $6.3 \pm 0.9$ days during the week of monitoring; approximately $4.6 \pm 0.7$ weekdays and $1.7 \pm 0.5$ weekend days. Average wear time across all days, weekdays, and weekend days was $13.9 \pm 1.9,14.2 \pm 1.9$, and 13.4 \pm 3.1 hours per day, respectively. Across all participants, the accelerometer recorded $3.3 \pm$ 2.5 hours per week of MVPA compared to $2.6 \pm 3.1$ and $15.3 \pm 12.9$ hours per week for the 
one-week and one-year recalls, respectively. Hours per week of MVPA were greater for males than females for all methods. No differences in physical activity were detected by race or weight status using the accelerometer. On the G-S Recall, non-overweight participants reported more moderate physical activity and MVPA compared to overweight individuals ( $p$ $\leq 0.05)$.

Correlation coefficients between the accelerometer mean counts/minute/day and hours per week of MVPA reported from the one-week and one-year recalls were $r=0.43$ and $r=0.38$, respectively. The association between accelerometer-derived and self-reported (G-S Recall) light intensity physical activity was low $(\mathrm{r}=0.04)$. Associations between other accelerometer-derived physical activity variables and the self-report methods were moderate in magnitude, ranging from $r=0.30$ to 0.50 for the One-Week GS Recall and from $r=0.31$ to 0.44 for the One-Year Recall (Figure 2).

The general linear models indicated no significant moderating effects of gender, race, or weight status (all $p>0.05$ ) on the association between self-reported and accelerometerdetermined physical activity, although two approached significance; the interaction between gender and moderate intensity PA for the GS-Recall $(\mathrm{p}=0.06)$ and the interaction between weight status and MVPA for the One-Year Recall $(\mathrm{p}=0.06)$.

When stratifying the sample by gender, the associations between the accelerometer and selfreported light intensity physical activity remained low for both males and females. For moderate, vigorous and MVPA, the associations between the accelerometer and self-report instruments remained modest to relatively strong, ranging from 0.20 to 0.43 (Figure 3A). While moderation was not statistically significant, it does appear that greater correlations with the accelerometer were observed for MVPA in females using the G-S Recall, and for vigorous physical activity in females using the One-Year Recall.

When stratifying by race, correlations between accelerometer-derived physical activity and self reports were relatively strong for VPA ( $r=0.37$ to 0.52 ) and MVPA ( $r=0.36$ to 0.47 ) for both whites and non-whites (Figure 3B). When stratifying by weight status, associations between accelerometer data and the G-S Recall for VPA and MVPA were slightly lower for non overweight participants ( $r=0.44$ and 0.30 , respectively) compared to overweight $(r=$ 0.53 to 0.49 ; Figure 2C). A similar finding was observed with the correlations for MVPA between the accelerometer and the One-Year Recall; Spearman $r=0.36$ for the non overweight and $\mathrm{r}=0.49$ for the overweight group.

Scatterplots of accelerometer-derived MVPA compared to self-reported MVPA are presented in Figure 4 for the G-S Recall and in Figure 5 for the One-Year Recall. Figure 4 demonstrates that the G-S Recall did not systematically over- or under-estimate MVPA compared to the accelerometer. Figure 5 demonstrates that the One-Year Recall severely overestimated hours per week spent in MVPA, compared to the accelerometer as the criterion measure.

Bland-Altman plots used to compare MVPA from the accelerometer with the G-S Recall and the One-Year Recall are presented in Figure 6. The wide confidence limits, especially for the One-Year Recall, indicate a general inability of either recall instrument to accurately assess individual physical activity level. There was little evidence of bias with increasing MVPA for the G-S Recall, although there is greater variability with higher levels of physical activity. In contrast, there was a strong bias for the One-Year Recall to overestimate MVPA with higher levels of mean physical activity. 


\section{DISCUSSION}

The purpose of this study was to validate two different survey instruments assessing physical activity (the brief One-Week G-S Recall and a more detailed One-Year Recall) using accelerometry as the criterion measure. The results of this study indicate that both selfreport instruments were significantly associated with most accelerometer variables, including time spent in MVPA, although participants significantly over-reported their MVPA on the One-Year Recall. In addition, the over-reporting of MVPA on the One-Year Recall was more pronounced with increasing levels of physical activity.

This bias is visually presented with the scatter plots and Bland-Altman plots, using the mean of the physical activity estimates on the $\mathrm{x}$-axis (mean of accelerometer and recall-derived MVPA). This observation may indicate that relatively more active young adults tend to overestimate their activity to a greater extent than those that are mostly sedentary. With more activities listed on a questionnaire, an active person participating in a variety of activities may have more opportunity to report engaging in those activities, even if it was for only a very brief period of time.

The Bland-Altman technique, derived from clinical investigations, places the mean of both measures on the $\mathrm{x}$-axis, to assess the mean magnitude of MVPA and the difference between the two measures on the y-axis. These parameters allow one to look at the differences between the measures across the range of mean values for MVPA. This procedure assumes that both methods being tested are measuring the same underlying construct. Some of the bias observed when comparing the One-Year Recall with the accelerometer data may be due to the fact that, while the accelerometer is measuring only intensity and duration of movement over one week, the One-Year Recall is measuring intensity and duration in a variety of activities over a much longer period. Therefore, both instruments are not likely measuring the same constructs, limiting the interpretation that is possible from the BlandAltman plots. For these instruments, the scatterplots may actually provide more accurate and interpretable results, although the finding that the One-Year Recall significantly overestimates physical activity, compared to the accelerometer, is consistent regardless of the method.

The associations between the one-week G-S recall and the accelerometer were relatively strong (Spearman $r=0.40$ for MVPA) for self-report instruments being validated against an accelerometer criterion measure. The original validation research using the $\mathrm{G}-\mathrm{S}$ recall in adults reported associations between reports of "strenuous exercise" and a submaximal fitness test $(r=0.35)$. Additional research using the G-S Recall reported associations with a Caltrac accelerometer $\left(\mathrm{r}=0.32^{20}\right.$ and $\left.\mathrm{r}=0.45^{19}\right)$ and measured aerobic fitness ranging from $\mathrm{r}=0.56$ to $0.57 .{ }^{20}$ The accelerometer used for the current study and the data processing techniques are more sophisticated than the Caltrac used in the Jacobs et al. study and may partially explain the higher correlations with accelerometry seen in the current study.

There are a number of physical activity questionnaires available for adult populations. 41,42 For example, the International Physical Activity Questionnaire (IPAQ), ${ }^{43}$ a one-week recall instrument, has recently been used in US and international settings. The original validation research of the IPAQ indicated acceptable validity ( $r=0.30)$ across several countries, "which was comparable to most other self-report validation studies". ${ }^{44}$ Additional studies of the IPAQ using an accelerometer as the criterion measure have observed similar validation correlations of $0.30-0.32,{ }^{45} \mathrm{r}=0.55,{ }^{46}$ and $\mathrm{r}=0.26$ to 0.36 in African-American adults. ${ }^{47}$ There have been reports that the original IPAQ (especially the long form) tends to overestimate physical activity in adults. ${ }^{48}$ This over-reporting is similar to the current finding that the One-Year Recall significantly over-estimated physical activity. Both 
instruments may suffer from the same limitation; the more questions asked, the more physical activity is reported.

Research using one-year physical activity recalls in young adults is limited. A number of historical physical activity questionnaires have been used in older populations to assess physical activity over various time frames. ${ }^{36-40}$ The research using these historical measures indicates acceptable test-retest reliability and validity (using a variety of criterion measures including accelerometers, fitness measures, and energy expenditure using doubly labeled water), similar in magnitude to the associations observed in the current study.

The One-Year Recall used for the current study was based on the recall used for the GUTS study. ${ }^{15}$ Using a measure of aerobic fitness (one-mile run time) in a sample of adolescents, Rifas-Shiman et al. ${ }^{15}$ observed significant associations with the one-year self-reports of physical activity ( $r=-0.41$ for girls, $r=-0.48$ for boys). The validity correlations observed in the current study using the accelerometer as the criterion measure are comparable although neither criterion measure is ideal. Current physical activity levels (measured with the accelerometer) may not reflect past-year physical activity and current aerobic fitness status may not reflect past year activity levels since fitness gains can begin to dissipate after only several weeks of detraining. Therefore, the associations presented in the current study are likely weakened by this discrepancy in time frames.

Since there is no other directly comparable data using a similar one-year self-report instrument in young adults, the data by Rifas-Shiman et al. using a nationally representative sample of 11-14 year olds provides a comparative study, with some caveats. ${ }^{15}$ RifasShiman et al. reported that MVPA for the females at 2 time points was $12.8 \mathrm{hrs} / \mathrm{wk}$ in 1996 and $10.4 \mathrm{hrs} /$ wk in 1997. Males reported $15.5 \mathrm{hrs} / \mathrm{wk}$ of MVPA in 1996 and $13.4 \mathrm{hrs} / \mathrm{wk}$ of MVPA in 1997. Our means of 10.1 and $17.3 \mathrm{hrs} / \mathrm{wk}$ of MVPA for females and males, respectively, are similar although slightly greater for the males than those reported by RifasShiman using the original GUTS instrument. Although our sample is older, which would tend to make them less active, we included transportation and work-related moderate and vigorous physical activity (not included on the original GUTS tool) which would tend to increase the amount of activity reported. Excluding self-reported work and transportation activity on the current One-Year Recall resulted in a slight decrease in MVPA to 9.1 and $16.3 \mathrm{hrs} / \mathrm{wk}$ of MVPA for females and males, respectively.

The current study used a stratified sampling scheme to ensure equal representation of participants regarding gender, race, and weight status to explore the potential moderating effects of these variables on the strength of the associations between the self-report measures and the accelerometer. Additional strengths include the use of a state-of-the-art accelerometer and comprehensive data processing procedure. A limitation of the current study is that there was only one week of accelerometry data. Multiple weeks of accelerometer data collection throughout the year would provide a better criterion measure for validation of the One-Year Recall and would also allow an analysis of seasonal effects on objectively measured physical activity in young adults.

In conclusion, researchers are faced with a dilemma when choosing the right physical activity measure for their study; validity, reliability, study design, participant characteristics and burden all need to be considered. Based on the associations observed in the current study, the one-week G-S Recall demonstrated adequate validity for determining physical activity rankings of large groups or populations. When a relatively simple measure of global physical activity is needed, the G-S Recall has the benefit of being short (three questions) and did not overestimate MVPA in the current study. The evaluation of the One-Year Recall indicates preliminary support for the use of this measure to rank individuals according to 
their activity levels. However, the One-Year Recall significantly overestimated MVPA. But, the One-Year Recall has the potential benefit of being able to identify which specific physical activities were performed within three activity domains; work, transportation and leisure-time. Additional research is warranted to further develop and evaluate one-year physical activity recalls in young adults to obtain better estimates of long-term levels of physical activity.

\section{References}

1. Centers for Disease Control and Prevention. Youth Risk Behavior Surveillance - United States, 2007. Morb Mortal Weekly Rep, MMWR. 2008; 57(SS-4):109.

2. Kjonniksen L, Torsheim T, Wold B. Tracking of leisure-time physical activity during adolescence and young adulthood: a 10-year longitudinal study. International Journal of Behavioral Nutrition and Physical Activity. 2008; 5(69)10.1186/1479-5868-1185-1169

3. Malina RM. Physical activity and fitness: pathways from childhood to adulthood. American Journal of Human Biology. 2001; 13(2):162-172. [PubMed: 11460860]

4. Malina RM. Tracking of physical activity across the lifespan. President's Council on Physical Fitness and Sports: Research Digest September. 2001; 3(14):1-8.

5. Twisk JWR, Kemper HCG, Van Mechelen W. Tracking of activity and fitness and the relationship with cardiovascular disease risk factors. Medicine and Science in Sports and Exercise. 2000; 32(8): 1455-1461. [PubMed: 10949012]

6. Gordon-Larsen P, Nelson MC, Popkin BM. Longitudinal physical activity and sedentary behavior trends: Adolescence to adulthood. American Journal of Preventive Medicine. 2004; 27(4):277-283. [PubMed: 15488356]

7. Nelson MC, Neumark-Sztainer D, Hannan PJ, Sirard J, Story M. Longitudinal and secular trends in physical activity and sedentary behavior during adolescence. Pediatrics. 2006; 118:e1627-1634. [PubMed: 17142492]

8. Trost SG, McIver KL, Pate RR. Conducting accelerometer-based activity assessments in field-based research. Medicine and Science in Sports and Exercise. 2005; 37(11 Supp):S531-S543. [PubMed: 16294116]

9. Masse LC, Fuemmeler BF, Anderson CB, et al. Accelerometer data reduction: a comparison of four reduction algorithms on select outcome variables. Medicine and Science in Sports and Exercise. 2005; 37(11 Suppl):S544-S554. [PubMed: 16294117]

10. Sirard JR, Pate RR. Physical activity assessment in children and adolescents. Sports Med. 2001; 31(6):439-454. [PubMed: 11394563]

11. Godin G, Shephard RJ. A simple method to assess exercise behavior in the community. Canadian Journal of Applied Sport Science. 1985; 10:141-146.

12. Sallis JF, Patterson TL, Buono MJ, Nader PR. Relation of cardiovascular fitness and physical activity to cardiovascular disease risk factors in children and adults. American Journal of Epidemiology. 1988; 127(5):933-941. [PubMed: 3358413]

13. Sallis JF, Buono MJ, Roby J, Micale FG, Nelson JA. Seven-day recall and other physical activity self-reports in children and adolescents. Medicine and Science in Sports and Exercise. 1993; 25(1):99-108. [PubMed: 8423762]

14. Berkey CS, Rockett HRH, Gillman MW, Colditz GA. One-Year Changes in Activity and in Inactivity Among 10- to 15-Year-Old Boys and Girls: Relationship to Change in Body Mass Index. Pediatrics. 2003; 111(4):836-843. [PubMed: 12671121]

15. Rifas-Shiman SL, Gillman MW, Field AE, et al. Comparing physical activity questionnaires for youth: Seasonal vs annual format. American Journal of Preventive Medicine. 2001; 20(4):282285. [PubMed: 11331117]

16. Neumark-Sztainer D, Croll J, Story M, Hannan PJ, French S, Perry C. Ethnic/racial differences in weight-related concerns and behaviors among adolescent girls and boys: Findings from Project EAT. Journal of Psychosomatic Research. 2002; 53:963-974. [PubMed: 12445586] 
17. Neumark-Sztainer D, Story M, Hannan PJ, Croll J. Overweight status and eating patterns among adolescents: Where do youth stand in comparison to the Healthy People 2010 Objectives? American Journal of Public Health. 2002; 92(5):844-851. [PubMed: 11988458]

18. Neumark-Sztainer D, Wall M, Guo J, Story M, Haines J, Eisenberg M. Obesity, disordered eating, and eating disorders in a longitudinal study of adolescents: How do dieters fare five years later? Journal of the American Dietetic Association. 2006; 106:559-568. [PubMed: 16567152]

19. Miller DJ, Freedson PS, Kline GM. Comparison of activity levels using the Caltrac accelerometer and five questionnaires. Med Sci Sports Exerc Mar. 1994; 26(3):376-382.

20. Jacobs DR, Ainsworth BE, Hartman TJ, Leon AS. A simultaneous evaluation of 10 commonly used physical activity questionnaires. Medicine and Science in Sports and Exercise. 1993; 25:8191. [PubMed: 8423759]

21. Bauer KW, Nelson MC, Boutelle KN, Neumark-Sztainer D. Parental influences on adolescents' physical activity and sedentary behavior: Longitudinal findings from Project EAT-II. International Journal of Behavioral Nutrition and Physical Activity. 2008; 5:12. [PubMed: 18302765]

22. Utter J, Neumark-Sztainer D, Jeffery R, Story M. Couch potatoes or French fries: Are sedentary behaviors associated with body mass index, physical activity, and dietary behaviors among adolescents? Journal of the American Dietetic Association. 2003; 103(10):1298-1305. [PubMed: 14520247]

23. Gortmaker SL, Cheung LW, Peterson KE, et al. Impact of a school-based interdisciplinary intervention on diet and physical activity among urban primary school children: eat well and keep moving. Arch Pediatr Adolesc Med. 1999; 153(9):975-983. [PubMed: 10482216]

24. Peterson, KE.; Field, AE.; Fox, MK., et al. Report to Division of School and Adolescent Health at the Centers for Disease Control and Prevention. Nutrition Department, Harvard School of Public Health; Validation of the Youth Risk Behavioral Surveillance System (YRBSS) questions on dietary behaviors and physical activity among adolescents in grades 9 through 12 . Available at: https://regepi.bwh.harvard.edu/health/KIDS/files/3.\%20Youth.Adolescent\%20Activity \%20Questionnaire/1.\%20YAAQ\%20Instructions

25. Ainsworth BE, Haskell WL, Whitt MC, et al. Compendium of physical activities: an update of activity codes and MET intensities. Medicine and Science in Sports and Exercise. 2000; 32(9 Suppl):S498-S504. [PubMed: 10993420]

26. Eston RG, Rowlands AV, Ingledew DK. Validity of heart rate, pedometry, and accelerometry for predicting the energy cost of children's activity. Journal of Applied Physiology. 1998; 84(1):362371. [PubMed: 9451658]

27. Louie L, Eston RG, Rowlands AV, et al. Validity of heart rate, pedometry, and accelerometry for estimating the energy cost of activity in Hong Kong Chinese boys. Pediatric Exercise Science. 1999; 11(3):229-239.

28. Trost SG, Ward DS, Moorehead SM, Watson PD, Riner W, Burke JR. Validity of the Computer Science and Applications (CSA) activity monitor in children. Medicine and Science in Sports and Exercise. 1998; 30(4):629-633. [PubMed: 9565947]

29. Sirard JR, Riner WF Jr, McIver KL, Pate RR. Physical activity and active commuting to elementary school. Medicine and Science in Sports and Exercise. 2005; 37(12):2062-2069. [PubMed: 16331130]

30. Sirard JR, Kubik MY, Fulkerson JA, Arcan C. Objectively measured physical activity in urban alternative high school students. Medicine and Science in Sports and Exercise. 2008; 40(12):20882095. [PubMed: 18981940]

31. Hurling R, Catt M, Boni M. Using internet and mobile phone technology to deliver an automated physical activity program: randomized controlled trial. Journal of Medical Internet Research. 2007; 9(2)10.2196/jmir.2199.2192.e2197

32. Jago R, Wedderkopp N, Kristensen PL, et al. Six-year change in youth physical activity and effect on fasting insulin and HOMA-IR. American Journal of Preventive Medicine. 2008; 35(6):554560. [PubMed: 18848414]

33. Mattocks C, Ness A, Leary S, et al. Use of Accelerometers in a Large Field-Based Study of Children: Protocols, Design Issues, and Effects on Precision. Journal of Physical Activity \& Health. 2008; 5:S98-S111. [PubMed: 18364528] 
34. Trost SG, Pate RR, Freedson PS, Sallis JF, Taylor WC. Using objective physical activity measures with youth: How many days of monitoring are needed? Medicine and Science in Sports and Exercise. 2000; 32(2):426-431. [PubMed: 10694127]

35. Troiano RP, Berrigan D, Dodd KW, Masse LC, Tilert T, McDowell M. Physical activity in the United States measured by accelerometer. Medicine and Science in Sports and Exercise. 2008; 40(1):181-188. [PubMed: 18091006]

36. Besson H, Harwood C, Ekelund U, et al. Validation of the historical adulthood physical activity questionnaire (HAPAQ) against objective measurements of physical activity. International Journal of Behavioral Nutrition and Physical Activity. 2010; 7(1)

37. Kriska AM, Sandler RB, Cauley JA, LaPorte RE, Hom DL, Pambianco G. The assessment of historical physical activity and its relation to adult bone parameters. American Journal of Epidemiology. 1988; 127:1053-1063. [PubMed: 3358406]

38. Kriska AM, Knowler WC, LaPorte RE, et al. Development of questionnaire to examine relationship of physical activity and diabetes in Pima Indians. Diabetes Care. 1990; 13:401-411. [PubMed: 2318100]

39. Schulz LG, Harper IT, Smith CJ, Kriska AM, Ravussin E. Energy intake and physical activity in Pima Indians: comparisons with energy expenditure measured by doubly-labeled water. Obesity Research. 1994; 2:541-548. [PubMed: 16355515]

40. Winters-Hart CS, Brach JS, Storti KL, Trauth JM, Kriska AM. validity of a questionnaire to assess historical physical activity in older women. Medicine and Science in Sports and Exercise. 2004; 36(12):2082-2087. [PubMed: 15570143]

41. Kriska AM, Caspersen CJ. A collection of physical activity questionnaires for health-related research. Medicine and Science in Sports and Exercise. 1997; 29(6 Suppl):S1-S205. [PubMed: 9243481]

42. Sallis JF, Saelens BE. Assessment of physical activity by self-report. Status, limitations, and future directions. Research Quarterly for Exercise and Sport. 2000; 71(2 Suppl):S1-S14. [PubMed: 10925819]

43. International Physical Activity Questionnaire Core Group. [Accessed May 18, 2010] Guidelines for the data processing and analysis of the International Physical Activity Questionnaire. Available at: http://www.ipaq.ki.se/scoring.htm

44. Craig CL, Marshall AL, Sjostrom M, et al. International physical activity questionnaire: 12-country reliability and validity. Medicine and Science in Sports and Exercise. 2003; 35(8):1381-1395. [PubMed: 12900694]

45. Boon RM, Hamlin MJ, Steel GD. Validation of the New Zealand Physical Activity Questionnaire (NZPAQ-LF) and the International Physical Activity Questionnaire (IPAQ-LF) with accelerometry. British Journal of Sports Medicine. 200810.1136/bjsm.2008.052167

46. Hagstromer M, Oja P, Sjostrom M. The International Physical Activity Questionnaire (IPAQ): a study of concurrent and construct validity. Public Health Nutr. 2006; 9(6):755-762. [PubMed: 16925881]

47. Wolin KY, Heil DP, Askew S, Matthews CE, Bennett GG. Validation of the International Physical Activity Questionnaire-Short among Blacks. Journal of Physical Activity \& Health. 2008; 5(5): 746-760. [PubMed: 18820348]

48. Rzewnicki R, Vanden Auweele Y, De BI. Addressing overreporting on the International Physical Activity Questionnaire (IPAQ) telephone survey with a population sample. Public Health Nutr. 2003; 6(3):299-305. [PubMed: 12740079] 
90. Not including work- or transportation-related activity, what have you done in the past YEAR? Mark "None/Zero" for any season you did not do that activity.

a. Walking or Hiking (for fun/exercise; include walking on a treadmill and around the golf course) Did you do this activity over the past year?

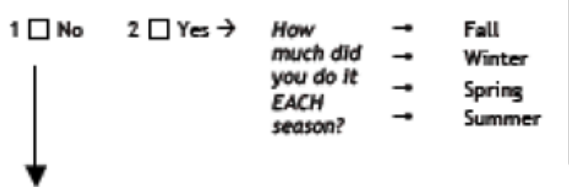

$\left|\begin{array}{c}\text { Nonel } \\ \text { Zero } \\ \square \\ \square \\ \square \\ \square\end{array}\right|$

\begin{tabular}{c|c|}
$\begin{array}{c}\text { Less } \\
\text { than } 1 / 2 \\
\text { hr/wk }\end{array}$ & $\begin{array}{c}\text { 1/2-less } \\
\text { than 2 } \\
\text { hr/wk }\end{array}$ \\
$\square$ & $\square$ \\
$\square$ & $\square$ \\
$\square$ & $\square$ \\
$\square$ & $\square$ \\
\hline$口$
\end{tabular}

\begin{tabular}{|c|c|c|c|c|}
\hline $\begin{array}{c}2-3 \\
\mathrm{hr} / \mathrm{wk}\end{array}$ & $\begin{array}{c}4-6 \\
\text { hr/wk }\end{array}$ & $\begin{array}{c}7-9 \\
h r / w k\end{array}$ & $\begin{array}{c}10+ \\
\text { hr/wk }\end{array}$ & 257 \\
\hline $\begin{array}{l}\text { ㅁ } \\
\square \\
\square \\
\square\end{array}$ & $\begin{array}{l}\text { ㅁ } \\
\square \\
\square \\
\square\end{array}$ & $\begin{array}{l}\square \\
\square \\
\square \\
\square\end{array}$ & $\begin{array}{l}\square \\
\square \\
\square \\
\square\end{array}$ & $\begin{array}{l}150 \\
1300 \\
\$ 00 \\
\$ 01\end{array}$ \\
\hline
\end{tabular}

Figure 1.

Sample question from the One-Year Recall 


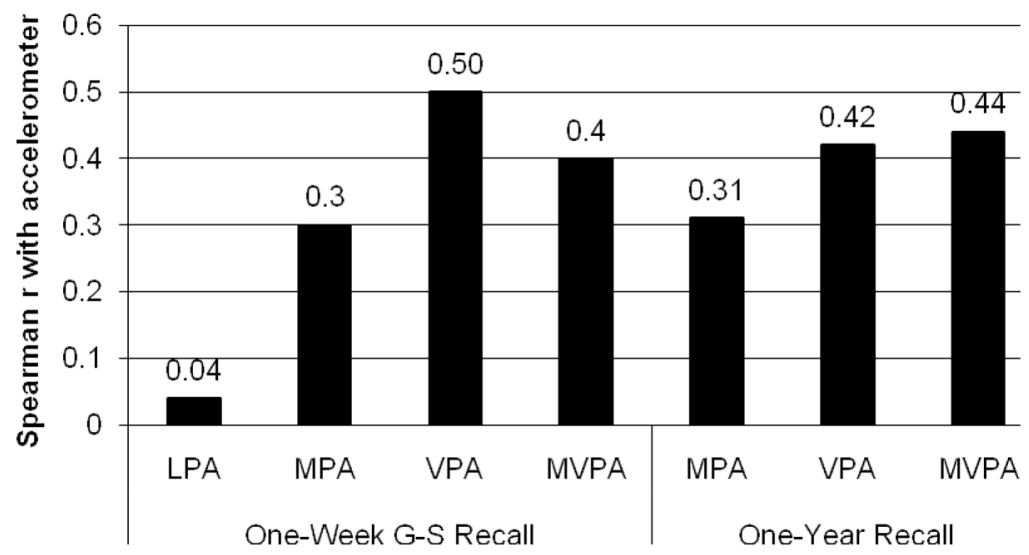

Figure 2. Spearman correlations between accelerometer-derived physical activity variables and self-reports

G-S Recall, Godin-Shephard One Week Physical Activity Recall

LPA, mean hours of light intensity physical activity per week MPA, mean hours of moderate intensity physical activity per week VPA, mean hours of vigorous intensity physical activity per week MVPA, mean hours of moderate and vigorous intensity physical activity per week 


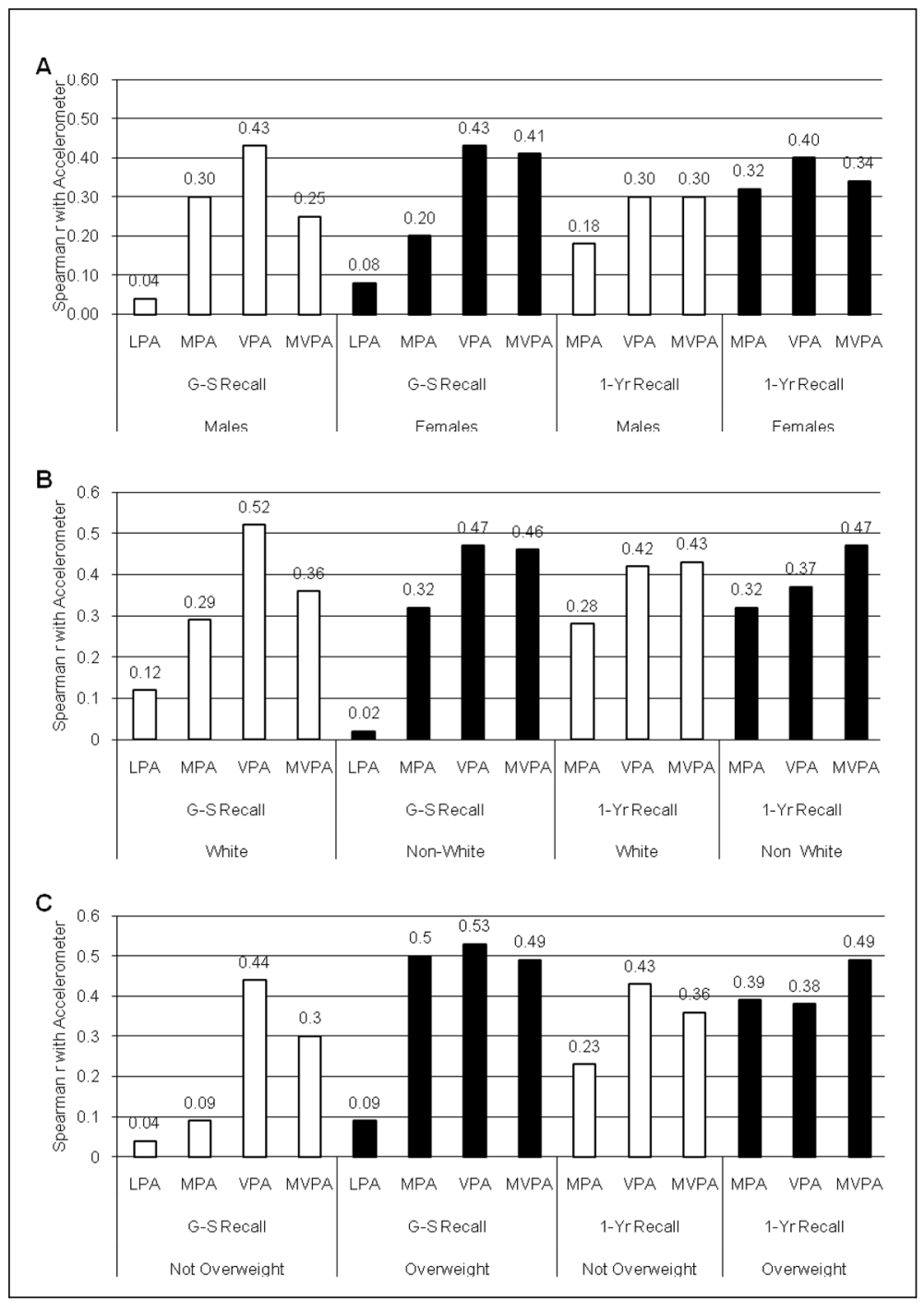

Figure 3.

Figure 3A-C: Spearman correlations between accelerometer-derived physical activity variables and self-reports stratified by gender (A), race (B), and weight status (C) G-S Recall, Godin-Shephard One Week Physical Activity Recall LPA, mean hours of light intensity physical activity per week MPA, mean hours of moderate intensity physical activity per week VPA, mean hours of vigorous intensity physical activity per week MVPA, mean hours of moderate and vigorous intensity physical activity per week 


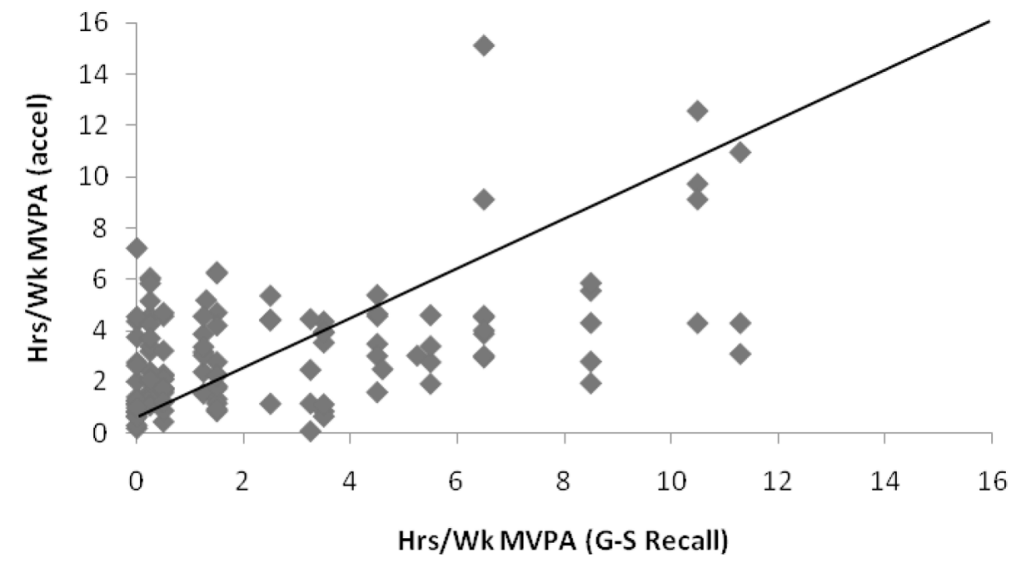

Figure 4. Scatterplot of mean hours per week of MVPA self-reported on the G-S Recall and recorded by the accelerometer

MVPA, moderate and vigorous physical activity

G-S Recall, Godin-Shephard One Week Physical Activity Recall 


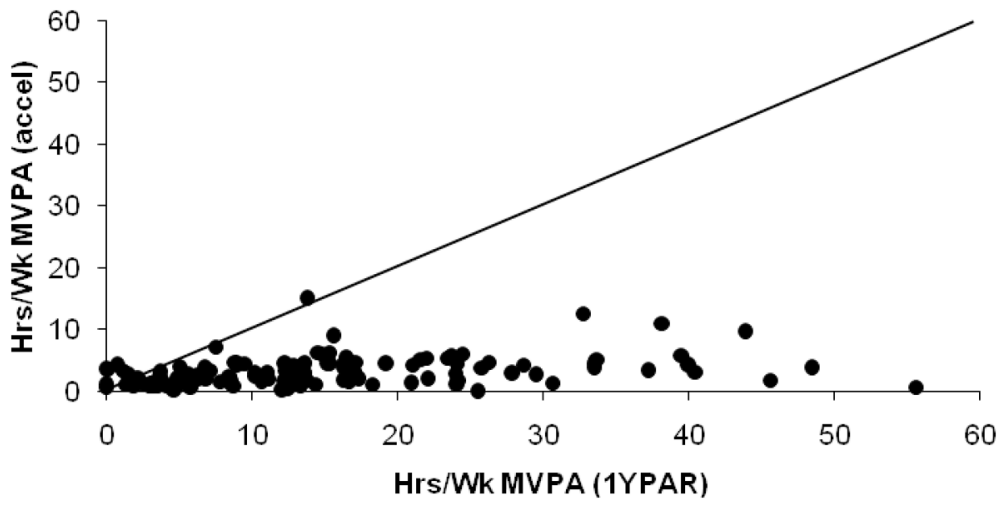

Figure 5. Scatterplot of mean hours per week of MVPA self-reported on the One-Year Recall and recorded by the accelerometer MVPA, moderate and vigorous physical activity 1YPAR, One-Year Physical Activity Recall 

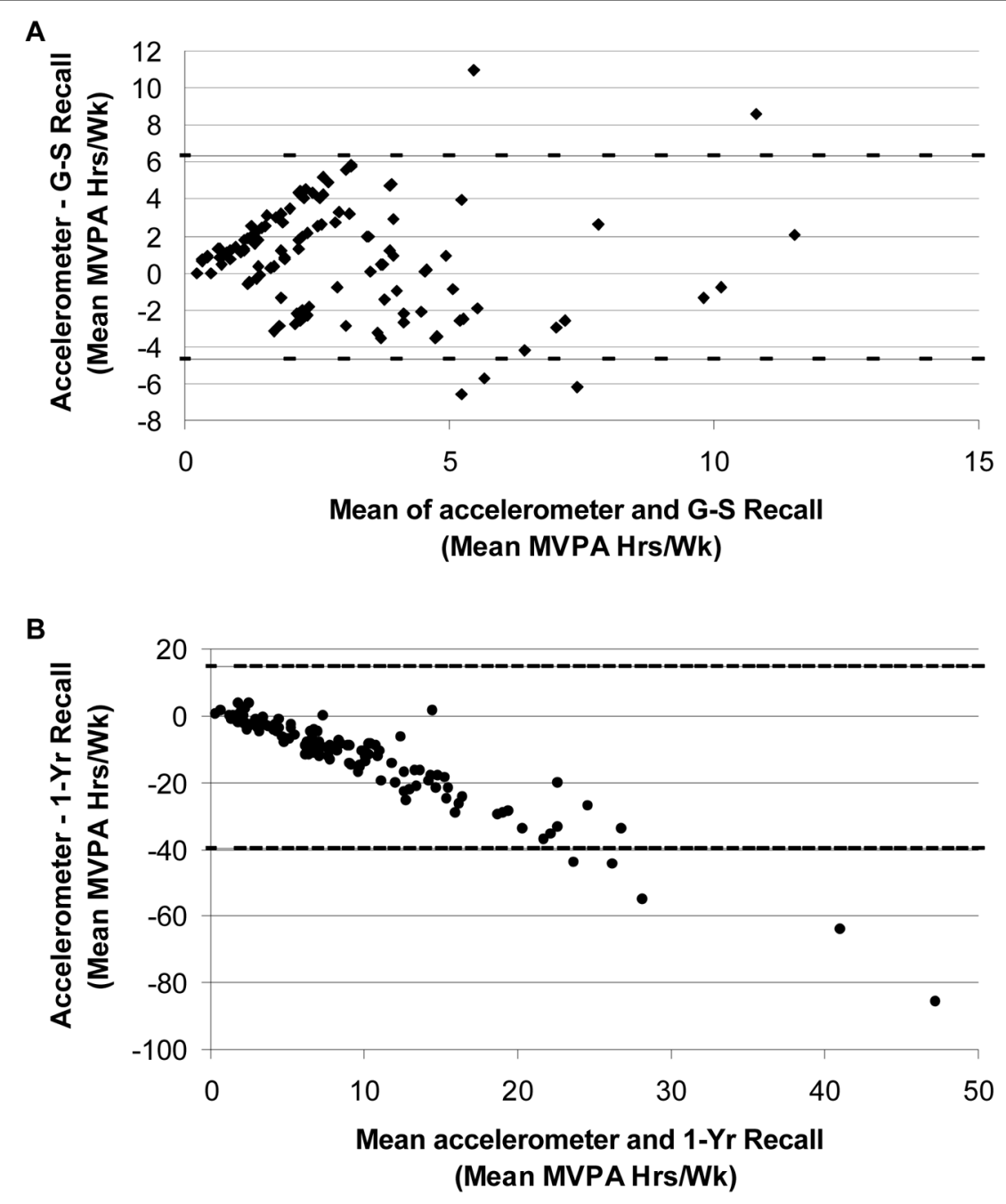

Figure 6.

Figure 6 A-B: Bland-Altman plots with $95 \%$ confidence limits comparing MVPA measured by accelerometer, G-S Recall (A) and One-Year Recall (B)

G-S Recall, Godin-Shephard One Week Physical Activity Recall 


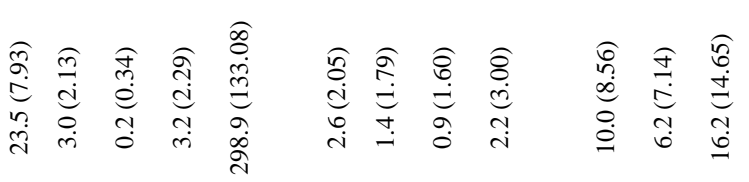

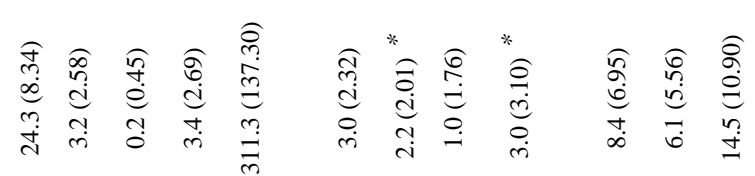

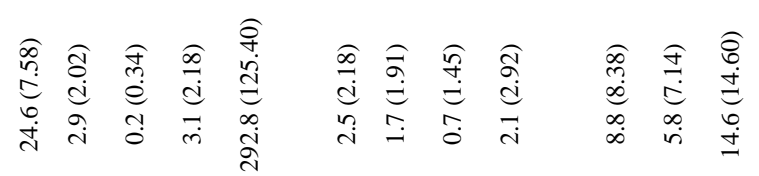

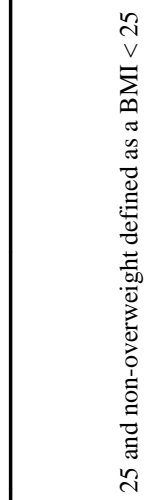

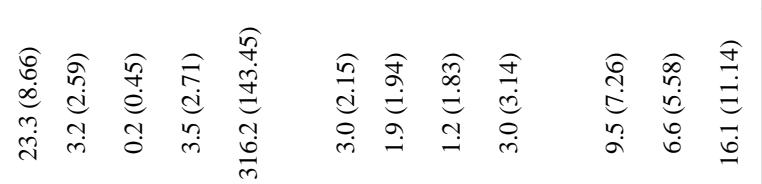

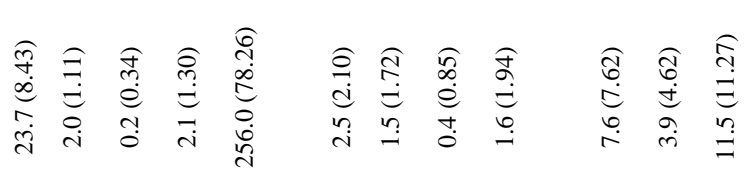

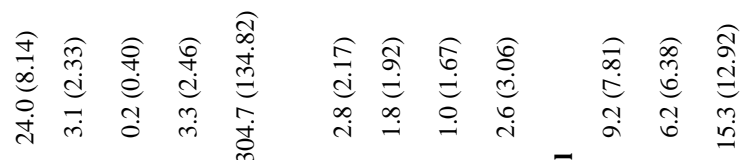

